\title{
Microtubule Polarity and Distribution in Teleost Photoreceptors
}

\author{
Louise Leotta Troutt and Beth Burnside \\ Department of Physiology-Anatomy, University of California, Berkeley, California 94720
}

\begin{abstract}
We have characterized the polarity orientation of microtubules in teleost retinal photoreceptors. The highly polarized rods and cones contain large numbers of paraxially aligned microtubules and exhibit dramatic cell shape changes. The myoid portion of the inner segments of both rods and cones undergoes contraction and elongation in response to light or circadian signals. Previous studies in our laboratory have demonstrated that in cones but not rods myoid elongation is microtubule-dependent. To determine polarity orientation, we decorated microtubules in photoreceptors of the green sunfish Lepomis cyanellus, with hooks formed from either exogenous or endogenous tubulin subunits. The direction of curvature of the attached hooks in cross section indicates microtubule polarity orientation by allowing one to determine the relative positions within the cell of the plus (fast-growing) and minus (slow-growing) ends of the microtubules. We found that virtually all cytoplasmic microtubules in photoreceptors are oriented with plus ends directed toward the synapse and minus ends toward the basal body at the base of the outer segment. Axonemal microtubules in photoreceptor outer segments are oriented with minus ends toward the basal body as in cilia and flagella. We have suggested previously that cone myoid elongation is mediated by mechanochemical sliding between microtubules. The polarity observations reported here indicate that if microtubules do slide in cones, sliding would necessarily occur between microtubules of parallel orientation as is observed in cilia and flagella.
\end{abstract}

Microtubules are known to be involved in many aspects of cellular motility, including axonal transport (Friede and Ho, 1977; Hammond and Smith, 1977; Allen et al., 1985), pigment migration (Malawista, 1971; Schliwa and Bereiter-Hahn, 1973; Murphy and Tilney, 1974), mitosis (Inoue and Sato, 1967), and phagocytosis (Stossel, 1974). They also play crucial roles in the clongation of cells or cell projections, as in developing neurons or embryonic epithelia (Stephens and Edds, 1976). However, the mechanism by which microtubules contribute to cell shape change remains enigmatic: it is not even clear whether they participate directly in the motive forces producing these movements.

In our laboratory, we have been using the photoreceptors of the green sunfish, Lepomis cyanellus, as models for studying

\footnotetext{
Received May 27, 1987; revised Nov. 9, 1987; accepted Nov. 11, 1987.

We would like to thank Drs. Allen Dearry, Ursula Euteneuer, and Kathryn Pagh Roehl for critical reading of the manuscript. In addition, we thank Dr. Euteneuer for helpful discussions of methods and Hoa Trinh for helping to prepare the manuscript. This work was supported by NIH Grant EYO3575 and NSF Grant DCB-8608751.

Correspondence should be addressed to Beth Burnside at the above address. Copyright (C) 1988 Society for Neuroscience $0270-6474 / 88 / 072371-10 \$ 02.00 / 0$
}

microtubule function in cell shape change. In fish, amphibians, and birds, both rods and cones undergo extensive length changes in response to changes in lighting conditions: onset of darkness induces cone elongation and rod contraction, while onset of light induces opposite movements (Ali, 1975; Burnside and Nagle, 1983). These movements serve to position the photoreceptors appropriately for vision under bright or dim light conditions. During the day, cones (the bright-light receptors) are contracted to occupy the entire light capture area of the retina, thus maximally exposing their outer segments to incoming light. During the night, rods the dim-light receptors) are contracted to position themselves optimally for light reception.

Cone length changes are mediated by the cell's necklike myoid region, which contains numerous paraxially aligned microtubules (Fig. 1). In green sunfish, cone myoids contract in the light to a length of $2-4 \mu \mathrm{m}$; in the dark, their myoids elongate to as much as $100 \mu \mathrm{m}$. Inhibitor studies have shown that cone myoid elongation is microtubule-dependent and that contraction is actin-dependent (Burnside, 1976, 1988a; Warren and Burnside, 1978; Burnside et al., 1982). Although microtubules are required for cone elongation, their role in force production is yet unclear. Effects of vanadate, erythro-9-[3-2-(hydroxynonyl)]adenine (EHNA) and $N$-ethylmaleimide (NEM) on reactivated cone elongation in lysed cell models are consistent with a possible role for a dynein-like ATPase in microtubule-based force production for cone elongation (Burnside, 1988b).

In rods, both elongation and contraction are actin-based: cytochalasin treatment blocks both movements, whereas disruption of microtubules by cold and nocadazole has no effect on rod length changes (O'Connor and Burnside, 1981, 1982). Though microtubules are present in the rod myoid, they are not required for elongation; perhaps they provide some structural support. Since the role of microtubules in rod elongation differs so dramatically from that in cones, we have taken this opportunity to compare polarity orientations in these 2 closely related and morphologically similar cells. Though mechanisms of elongation differ in these 2 cell types, microtubule roles in intracellular transport might be expected to be similar.

Microtubules are functionally polarized in that the 2 ends display different polymerization kinetics: at the plus end, the critical concentration for assembly is lower than at the minus end (Allen and Borisy, 1974; Dentler et al., 1974; Margolis and Wilson, 1981). The polarity orientation of a microtubule plays an important role in its function. In cilia and flagella, it is well established that dynein-mediated sliding occurs between microtubules of the same polarity orientation (Sale and Satir, 1977; Euteneuer and McIntosh, $1981 \mathrm{a}, \mathrm{b})$. On the other hand, if the mitotic spindle elongates by a microtubule sliding mechanism as has been suggested (McDonald et al., 1979; Yoshida et al., 1985; Cande and McDonald, 1986), sliding would occur be- 


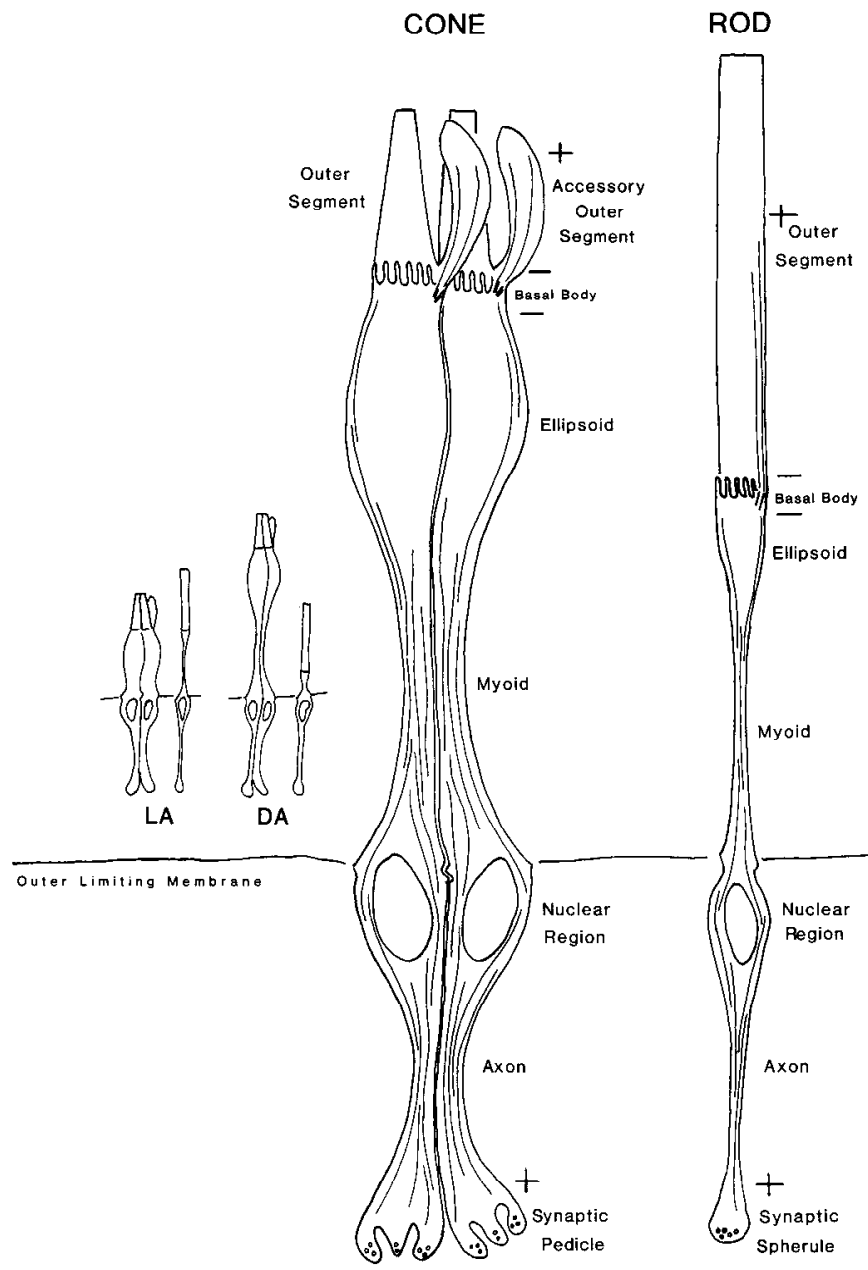

Figure 1. Distributions of microtubules in teleost photoreceptors. Plus and minus designations indicate the polarity orientations (plus and minus ends) of cytoplasmic microtubules and of axonemal microtubules of the outer segment and accessory outer segment. Rod and cone movements associated with light-adapted $(L A)$ and dark-adapted $(D A)$ retinomotor positions are shown in the insert.

tween microtubules of opposite polarity orientation in this system. Microtubule-dependent translocator molecules called kinesins that transport particles along a microtubule toward its plus end have been isolated (Vale et al., 1985; Pryer et al., 1986). Other axonal translocators have been isolated which move particles toward a microtubule minus end (Vale et al., 1985). Microtubule polarity confers direction to pigment transport in chromatophores (McNiven and Porter, 1986).

Recently developed procedures have made it possible to determine the polarity orientation of microtubules in situ in a variety of cell types. The microtubules are decorated with hooks formed from exogenous tubulin subunits (Heidemann and McIntosh, 1980; McIntosh and Euteneuer, 1984) or with ciliary or flagellar dynein (Telzer and Haimo, 1981). In the hook method, proper buffer conditions (including high ionic strength and a small amount of DMSO) induce tubulin subunits to assemble into curved sheets of protofilaments along the walls of preexisting microtubules. In cross section these sheets appear as hooked appendages attached to the side of the microtubules. The direction of curvature of the hooks, clockwise or counterclockwise, allows one to determine microtubule polarity orientation.
We have employed the tubulin hook method to examine the polarity orientations of the microtubules in green sunfish photoreceptors. We find that in both cones and rods, microtubules of the cell body are virtually all oriented parallel to one another, with plus ends directed toward the synaptic end of the cell and minus ends directed toward the basal body at the base of the outer segment. Because multiple hooks were rare on microtubulcs of photorcceptor outer segments, our observations are less conclusive for this part of the cell. Nonetheless, all microtubules with identifiable hooks in the outer segments were directed opposite those in the cell body, with their minus ends toward the basal body of the outer segment and plus ends toward the distal tip of the outer segment, as in motile cilia.

\section{Materials and Methods}

Tubulin preparation. Microtubule protein was prepared from bovine brain by the method of Shelanski et al. (1973) using glycerol through 2 cycles of assembly/disassembly. The depolymerized tubulin in PMEG buffer consisting of $0.5 \mathrm{M}$ Pipes buffer, $\mathrm{pH} 6.9,1 \mathrm{~mm} \mathrm{MgCl}_{2}, 1 \mathrm{~mm}$ EGTA, and $1 \mathrm{mM}$ GTP was centrifuged at $250,000 \times \mathrm{g}$ for $2.5 \mathrm{hr}$ to obtain the high-speed supernate that was used in decoration experiments.

Animals. All experiments were performed on retinas of green sunfish (Lepomis cyanellus) obtained from Chico Game Fish Farm, CA, and maintained in an outdoor pond.

Preparation of retinas. Fish were dark-adapted by placing them in an aerated dark box for a time that allowed the cone myoids to elongate to a length of approximately $30 \mu \mathrm{m}$. The amount of time required varied from 25 to 40 min depending on the season of the year. All subsequent procedures were carried out in the light. Fish were killed by spinal section and their eyes removed. Retinas were detached from the eyecup by a stream of calcium-free Earle's Ringer solution containing 5 mM EGTA, $1 \mathrm{mM} \mathrm{MgSO}_{4}, 24 \mathrm{~mm}$ sodium bicarbonate, $25 \mathrm{~mm}$ glucose, 3 mM HEPES, $1 \mathrm{~mm}$ ascorbate, $\mathrm{pH} 7.4$, directed between the retina and the choroid. The retina was freed from the retinal pigment epithelium and eyecup by severing the optic nerve. Retinas were bisected along the choroid fissure and pieces $2 \mathrm{~mm}^{2}$ were cut from the central region of each hall retina.

Decoration of microtubules by exogenous tubulin. Microtubule decoration was carried out by a modification of the procedure reported by Euteneuer and McIntosh (1980). The $2 \mathrm{~mm}^{2}$ pieces of retina were incubated in $0.5 \mathrm{ml}$ of a buffer that served to both permeablize the cells and promote assembly of hooked appendages onto preexisting microtubules. It consisted of $1 \%$ Triton X-100, $0.5 \%$ deoxycholate, $0.2 \% \mathrm{SDS}$, $2.5 \% \mathrm{DMSO}$, and $1.8 \mathrm{mg} / \mathrm{ml}$ tubulin in 0.5 PMEG (Euteneuer and McIntosh, 1980, 1981a; Heidemann and McIntosh, 1980). Incubation was first carried out at $0^{\circ} \mathrm{C}$ for $30 \mathrm{~min}$ to prevent polymerization of tubulin during the time required for the detergents to penetrate a thick piece of tissue and lyse the cells sufficiently to allow tubulin subunits and medium constituents to enter the cells. Incubation was continued at room temperature $\left(22^{\circ} \mathrm{C}\right)$ for $10-15 \mathrm{~min}$ and then at $37^{\circ} \mathrm{C}$ for $15 \mathrm{~min}$ to promote free tubulin assembly into hooks. Hooks did not form unless the incubation temperature was increased to $37^{\circ} \mathrm{C}$. As controls, either the cold step was omitted (the tissue being incubated in the same medium at $22^{\circ} \mathrm{C}$ for $10-15 \mathrm{~min}$ and then $37^{\circ} \mathrm{C}$ for $15 \mathrm{~min}$ ) or exogenous tubulin or GTP was omitted.

Decoration of microtubules by endogenous tubulin. The above controls revealed that microtubules in green sunfish photoreceptors were only sparsely decorated without the cold incubation but could be decorated when incubated in the cold with or without the addition of exogenous tubulin to the incubation medium. Microtubules were extensively decorated even when $2 \mathrm{~mm}^{2}$ pieces of retina were incubated in $0.5 \mathrm{ml}$ of $1 \%$ Triton X-100, $0.5 \%$ deoxycholate, $0.2 \%$ SDS, $2.5 \%$ DMSO in PMEG, first at $0^{\circ} \mathrm{C}$ for $30 \mathrm{~min}$, then $22^{\circ} \mathrm{C}$ for $10 \mathrm{~min}$, and finally $37^{\circ} \mathrm{C}$ for 15 min with no exogenous tubulin.

As a further control for this decoration by endogenous tubulin, either the cold step was omitted or GTP was eliminated from the buffer.

Electron microscopy. After the above treatments, tissue squares were fixed in $2 \%$ glutaraldehyde in $50 \mathrm{~mm}$ cacodylate plus $5 \mathrm{~mm} \mathrm{CaCl}_{2}, \mathrm{pH}$ 7.4 , for $30 \mathrm{~min}$, washed in the same buffer, then postfixed in $0.5 \% \mathrm{OsO}_{4}$ plus $0.8 \% \mathrm{~K}_{3} \mathrm{Fe}(\mathrm{CN})_{6}$ in cacodylate for $30 \mathrm{~min}$. They were again washed in cacodylate, then in deionized, distilled water, and stained in $1 \%$ 
aqueous uranyl acetate for $1.5 \mathrm{hr}$ in the dark. After dehydration through an acetone series, they were infiltrated and embedded in Poly/Bed 812 resin.

Silver sections were cut on a Sorvall MT-2 ultramicrotome, stained with uranyl acetate and lead citrate and observed with a JEOL 100-S electron microscope.

Microtubule polarity in cones and rods. Microtubule polarity was determined by assessing the direction of curvature of hooks attached to microtubules in photographs taken from retina cross sections including both rods and cones $(\times 60,000-65,000)$. Hook curvature is directly related to microtubule polarity (Euteneuer and McIntosh, 1980, 1981a; Heidemann and McIntosh, 1980): a clockwise hook indicates that the observer is looking toward the minus end of the microtubule, while a counterclockwise hook indicates that one is looking toward the plus end. To establish the reliability of the assay when microtubules are decorated by endogenous tubulin, Table 1 follows the scoring procedure of McIntosh and Euteneuer (1984), according to which microtubules with more than one hook in the same direction were scored as "certain" microtubules of that polarity, while microtubules with one hook were scored separately, and microtubules possessing hooks in both directions were scored as "ambiguous." Once this reliability was assured, microtubules with 1 or more hooks in the same direction were counted together, as in Tables 2 and 3. In many cases decoration became elaborate, with one microtubule possessing up to 6 hooks. Microtubule decoration also occasionally produced connections between microtubules and images resembling microtubule doublets; these forms were counted in calculating the percentage decorated microtubules but were not scored for polarity. Hooks upon hooks were disregarded.

\section{Results}

Microtubule distribution in teleost retinal cones and rods

The distribution of microtubules in teleost cones has been previously investigated by both electron microscopy and immunofluorescence (Warren and Burnside, 1978; Nagle et al., 1986). Paraxially aligned microtubules are found throughout the entire length of the cone (Fig. 1). In teleost cones, the photoreceptor outer segment is accompanied by an accessory outer segment, both being attached to the cell by the slender connecting cilium that arises from a basal body located at the distal tip of the ellipsoid. Cytoplasmic microtubules of the connecting cilium splay as they project into the accessory outer segment and into the cytoplasmic bridge lying between the accessory and true outer segments (Fig. 2). Nine doublets are found near the basal body in the connecting cilium, but in the proximal region of the accessory outer segment, doublets convert to singlet microtubules (Fig. $2 b-d$ ). The basal body itself has the usual structure of 9 triplet microtubules surrounded by dense amorphous material; however, unlike most basal bodies, the cone triplets are not aligned in parallel into a cylinder but diverge (Fig. 2e). Projections ending with footlike structures emanating from the triplets may serve an anchoring function (Fig. 2a). Although an accessory centriole associated with the basal body has been reported for frog and mammalian cones (Tokyuaso and Yamada, 1959; Kinney and Fisher, 1978; Greiner et al., 1981), we detected none in green sunfish cones. However, as demonstrated in Figure $2 e$, a dense body with fine filaments radiating from it is sometimes seen near the basal body. A crowded aggregation of mitochrondria occupies the center of the ellipsoid; thus, the longitudinally arranged microtubules are restricted to a thin sheath of cytoplasm lying directly under the plasma membrane. The microtubules continue into the myoid region, where their numbers vary with changes in myoid length, ranging from 80 100 in $75-\mu \mathrm{m}$-long myoids to $250-300$ in fully contracted myoids (Burnside, 1988a). Near the outer limiting membrane microtubules are directed around the nucleus in the thin sheath of perinuclear cytoplasm. Only 50-60 microtubules continue into the axon, a few actually extending into the synaptic pedicle.
In most telcosts, rods are much more slender than concs, and the numbers of microtubules found at each level of the cell body are much smaller. Myoids of both elongated and contracted rods contain 7-13 microtubules, and axons contain 8-10 microtubules. Unlike cones, rods contain a typical cylindrical basal body at the base of the connecting cilium. No accessory centriole has been detected. The doublets of the connecting cilium convert to singlets in the outer segment; however, they do not splay as they do in cones, but rather are contained within the outer segment alongside the stacked disks.

\section{Decoration by endogenous tubulin}

Results of experiments designed to evaluate the effects of various aspects of the microtubule decoration procedure are illustrated in Table 1, which presents data only for cone myoids; results for rod myoids were comparable. Numerous microtubules were decorated when retinas were incubated in decoration medium without exogenous tubulin if the cold incubation was included. Although the percentage of microtubules with multiple hooks was lower than after incubation with exogenous tubulin, the percentage showing any decoration remained high (Table 1). Analysis of polarity orientation of microtubules decorated in the absence of exogenous tubulin gave results exactly comparable to those obtained when exogenous tubulin was present (Tables 1 and 2). Thus, polarity determination using endogenous tubulin is accurate. Table 1 shows that the percentages of decorated microtubules bearing counterclockwise hooks were similar in all cases where incubation at 3 temperatures was carried out, regardless of the presence or absence of exogenous tubulin, i.e., $92.8 \%$ with both exogenous tubulin and GTP (treatment 2); $97.2 \%$ without tubulin and with GTP (treatment 3); and $92.1 \%$ without either tubulin or GTP (treatment 4). In each of these treatments some ambiguous microtubules or microtubules with clockwise hooks were found, although these were fewer in the absence of exogenous tubulin. For sunfish retinas, the $0^{\circ} \mathrm{C}$ incubation greatly increased the amount of microtubule decoration; when retinas were incubated with both exogenous tubulin and GIP but at only 22 and $37^{\circ} \mathrm{C}$ (treatment 5 in Table 1 ), only $2.6 \pm 0.7 \%$ of the microtubules per myoid cross section were decorated, and 65 of the 67 decorated microtubules observed had single clockwise hooks. No decoration occurred if both exogenous tubulin and the $0^{\circ} \mathrm{C}$ step were eliminated. The decoration of microtubules in the absence of exogenous tubulin suggests that even in the presence of detergents some endogenous pool of tubulin subunits is available in the cells for hook formation. In addition, our results indicate that exogenous GTP is not required to enhance hook assembly in this system (Table 1).

\section{Cone microtubule polarity}

Table 2 illustrates our observations of the microtubule polarity orientation of microtubules in cones with myoid lengths of 20 $30 \mu \mathrm{m}$, and decorated by endogenous tubulin. All sections were viewed as though looking toward the distal tip of the outer segment. We examined 13 cone accessory outer segments containing hooked microtubules, and all hooks curved in the same direction. Only one microtubule was found that possessed more than one counterclockwise hook, all other decorated microtubules displayed a single counterclockwise hook. Although a microtubule with a single hook could represent the natural appearance of the transition zone where doublet microtubules convert to singlets, the consistent direction of curvature of the 

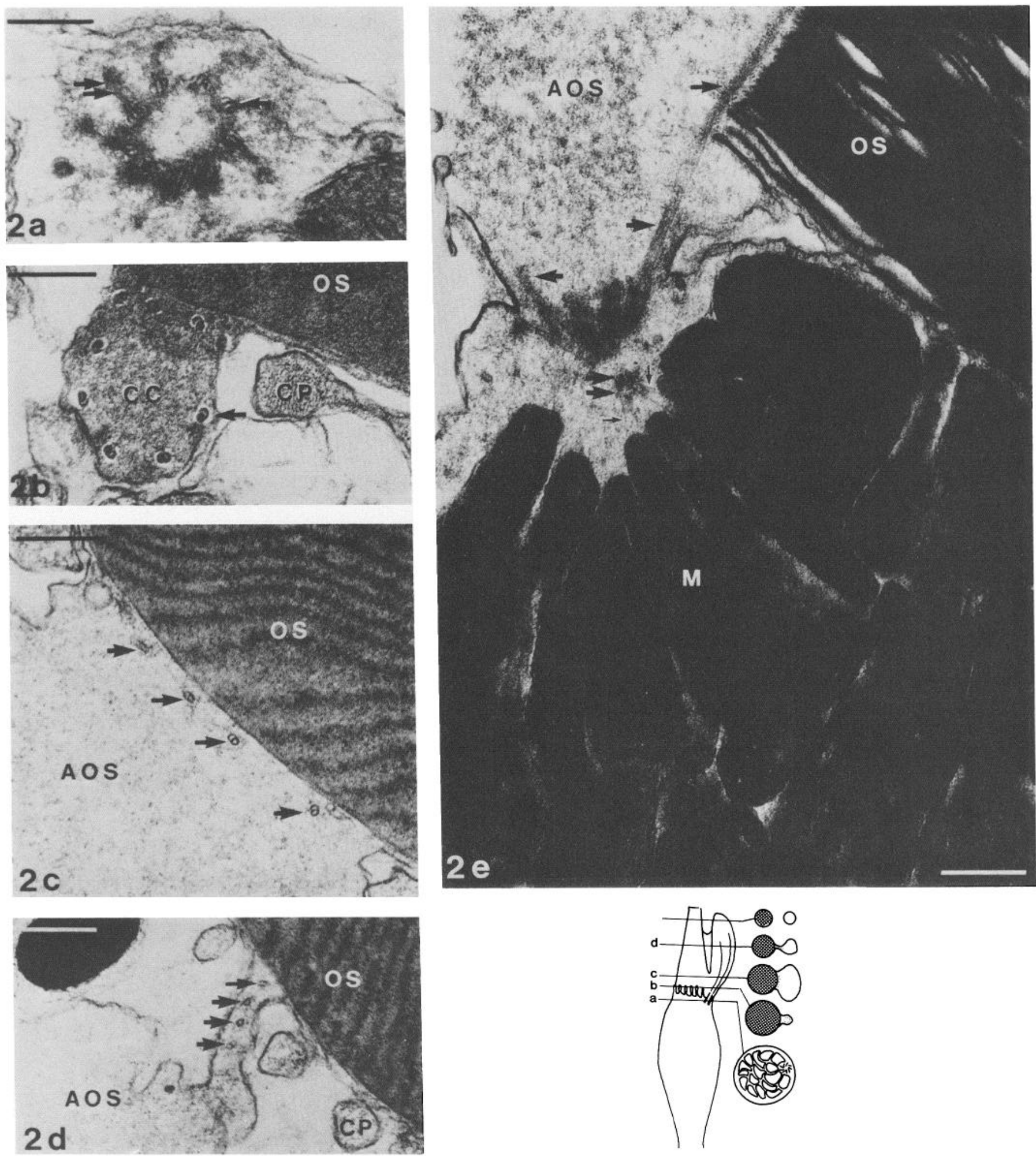

Figure 2. Microtubules of the cone basal body and accessory outer segment. $a-d$, Cross sections are arranged proximal to distal: $a$, triplet microtubules (arrow) of the basal body of the connecting cilium possess lateral projections (double arrows); $b$, doublet microtubules (arrows) near the base of the accessory outer segment retain the $9+0$ configuration; $c, 4$ doublets (arrows) lie adjacent to the outer segment, while the remaining microtubules splay into the amorphous matrix of the accessory outer segment; $d$, more distally, 4 singlets (arrows) are found in a cytoplasmic neck between accessory and true outer segments. $e$, Basal body in longitudinal section with nearby dense body (double arrow), filaments radiating toward ellipsoid mitochondria (small arrow), and microtubules extending into the accessory outer segment (large arrow). AOS, accessory outer segment, $O S$, true outer segment; $M$, mitochondrion; $C P$, calycal process; $C C$, connecting cilium. Scale bar, $0.25 \mu \mathrm{m}$. The line diagram illustrates the levels of $a-d$ in the cone upper ellipsoid, outer segment and accessory outer segment and the appearance of the entire cross section at each level. 
Table 1. Effects of treatment on microtubule decoration in cone myoids

\begin{tabular}{|c|c|c|c|c|c|c|c|c|}
\hline \multirow[b]{2}{*}{ Treatment } & \multirow[b]{2}{*}{$\begin{array}{l}\text { Number micro- } \\
\text { tubules/myoid } \\
{[X \pm \operatorname{SEM}(n)]}\end{array}$} & \multirow[b]{2}{*}{$\begin{array}{l}\text { Microtubules } \\
\text { decorated } \\
(\%)\end{array}$} & \multirow{2}{*}{$\begin{array}{l}\text { Number } \\
\text { decorated } \\
\text { micro- } \\
\text { tubules } \\
\text { scored }\end{array}$} & \multicolumn{2}{|c|}{$\begin{array}{l}\text { Plus end toward distal } \\
\text { tip OS }\end{array}$} & \multirow[b]{2}{*}{ Ambiguous } & \multicolumn{2}{|c|}{$\begin{array}{l}\text { Plus end toward } \\
\text { synapse }\end{array}$} \\
\hline & & & & $\begin{array}{l}\text { (>1 hook } \\
\text { counter- } \\
\text { clockwise) }\end{array}$ & $\begin{array}{l}1 \text { hook } \\
\text { counter- } \\
\text { clockwise }\end{array}$ & & $\begin{array}{l}1 \text { hook } \\
\text { clockwise }\end{array}$ & $\begin{array}{l}\text { "Certain" } \\
\text { (>1 hook } \\
\text { clockwise) }\end{array}$ \\
\hline 1. Untreated & $277.5 \pm 21.1(6)$ & 0 & - & - & - & - & - & - \\
\hline $\begin{aligned} \text { 2. } & 0,22,37^{\circ} \mathrm{C} \\
& + \text { tubulin }+ \text { GTP }\end{aligned}$ & $54.5 \pm 4.7$ & $59.0 \pm 3.9$ & 621 & $\begin{array}{l}3 \\
(0.5 \%)\end{array}$ & $\begin{array}{l}9 \\
(1.4 \%)\end{array}$ & $\begin{array}{l}33 \\
(5.3 \%)\end{array}$ & $\begin{array}{l}168 \\
(27.1 \%)\end{array}$ & $\begin{array}{l}408 \\
(65.7 \%)\end{array}$ \\
\hline 3. $\begin{aligned} & 0,22,37^{\circ} \mathrm{C} \\
& - \text { tubulin }+ \text { GTP }\end{aligned}$ & $92.5 \pm 3.2$ & $34.3 \pm 3.3$ & 107 & 0 & $\begin{array}{l}2 \\
(1.9 \%)\end{array}$ & $\begin{array}{l}1 \\
(0.9 \%)\end{array}$ & $\begin{array}{l}80 \\
(74.8 \%)\end{array}$ & $\begin{array}{l}24 \\
(22.4 \%)\end{array}$ \\
\hline $\begin{aligned} \text { 4. } & 0,22,37^{\circ} \mathrm{C} \\
& - \text { tubulin - GTP }\end{aligned}$ & $122.7 \pm 9.9$ & $76.4 \pm 7.2$ & 289 & 0 & $\begin{array}{l}13 \\
(4.5 \%)\end{array}$ & $\begin{array}{l}10 \\
(3.5 \%)\end{array}$ & $\begin{array}{l}169 \\
(58.5 \%)\end{array}$ & $\begin{array}{l}97 \\
(33.6 \%)\end{array}$ \\
\hline $\begin{aligned} \text { 5. } & -, 22,37^{\circ} \mathrm{C} \\
& + \text { tubulin }+ \text { GTP }\end{aligned}$ & $208.7 \pm 24.1(7)$ & $2.6 \pm 0.7$ & 67 & 0 & $\begin{array}{l}2 \\
(3.0 \%)\end{array}$ & 0 & $\begin{array}{l}65 \\
(97.0 \%)\end{array}$ & 0 \\
\hline $\begin{array}{l}\text { 6. } 0^{\circ} \mathrm{C},-,- \\
- \text { tubulin }+ \text { GTP }\end{array}$ & $63.6 \pm 10.5(9)$ & 0 & - & - & - & - & - & - \\
\hline
\end{tabular}

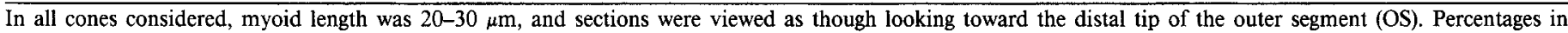

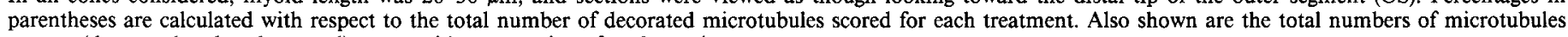
present (decorated and undecorated) per myoid cross section after the various treatments.

hooks and their correlation with multiply decorated microtubules in both rod and cone outer segments suggest that the hooks in such a zone would nonetheless indicate microtubule polarity. These observations then suggest that the microtubules in the accessory outer segment are oriented with minus ends toward the basal body and plus ends distal, consistent with microtubule orientation in motile cilia and flagella (Allen and Borisy, 1974; Euteneuer and McIntosh, 1981a).

In the cone cell body, virtually all decorated microtubules were found to be oriented with their plus ends toward the synapse and their minus ends toward the outer segment (Table 2). Within the 25 ellipsoids examined only clockwise hooks were found on microtubules. In 6 cone myoids (cf. Fig. 3), 97.2\% of the scored microtubules displayed one or more clockwise hooks. Of all the microtubules visible in a myoid in cross section, an average of $59 \pm 3.9 \%$ ( $n=6$ myoids) were decorated in some manner, although some of these microtubules could not be scored for polarity because of the nature of the decoration. In the region of the cone nucleus, $88.4 \%$ of those microtubules that could be scored for polarity bore one or more clockwise hooks. In 26 cone axons (Fig. 4), 96.6\% of the microtubules scored for polarity had clockwise hooks.

\section{Rod microtubule polarity}

Microtubule polarity distribution in rods was identical to that in cones (Table 3 ). In 33 rod outer segments containing hooked microtubules (Fig. 5), we found one microtubule with multiple counterclockwise hooks and 86 with a single counterclockwise hook. Again, the hooks could result from a transition of doublet microtubules to singlets, but the consistency of hook direction suggests that it reflects polarity, and it is consistent with multiply decorated outer segment microtubules. These observations suggest that rod outer segment microtubules are oriented with minus ends toward the basal body and plus ends distal, as in cones and in motile cilia.

In rod myoids and axons, virtually all decorated microtubules were oriented with plus ends distal toward the synaptic spherule, and minus ends toward the outer segment as described for cones (Table 3). In 26 rod myoids (Fig. 5), 98.0\% of the scored mi- crotubules displayed one or more clockwise hooks (again viewing toward the distal tip of the outer segment). Of all microtubules visible in a myoid cross section, an average of $88.6 \pm$ $3.6 \%$ ( $n=26$ myoids) were decorated in some manner, although not all of these could be scored for orientation. In 20 axons (Fig. 4), $98.7 \%$ of the microtubules scored for polarity had clockwise hooks (Table 3).

\section{Cold stability of cone microtubules}

Previous studies in our laboratory indicated that in green sunfish numerous cone microtubules were still present after intact retinas were incubated in Ringer's solution at $0^{\circ} \mathrm{C}$ or when lysed

Table 2. Microtubule polarity orientations in cones

\begin{tabular}{|c|c|c|c|c|}
\hline & $\begin{array}{l}\text { Number } \\
\text { of de- } \\
\text { corated } \\
\text { micro- } \\
\text { tubules } \\
\text { scored }\end{array}$ & $\begin{array}{l}\text { Plus end } \\
\text { toward } \\
\text { distal tip } \\
\text { OS-1 or } \\
\text { more hooks } \\
\text { counter- } \\
\text { clockwise }\end{array}$ & $\begin{array}{l}\text { Ambig- } \\
\text { uous }\end{array}$ & $\begin{array}{l}\text { Plus end } \\
\text { toward } \\
\text { synapse- } \\
\text { l or more } \\
\text { hooks } \\
\text { clockwise }\end{array}$ \\
\hline Accessory outer segment & 21 & $\begin{array}{c}21 \\
(100 \%)\end{array}$ & 0 & 0 \\
\hline Ellipsoid & 172 & 0 & 0 & $\begin{array}{l}172 \\
(100 \%)\end{array}$ \\
\hline Myoid & 107 & $\begin{array}{l}2 \\
(1.9 \%)\end{array}$ & $\begin{array}{l}1 \\
(0.9 \%)\end{array}$ & $\begin{array}{l}104 \\
(97.2 \%)\end{array}$ \\
\hline Perinuclear area & 181 & $\begin{array}{l}14 \\
(7.7 \%)\end{array}$ & $\begin{array}{l}7 \\
(3.9 \%)\end{array}$ & $\begin{array}{l}160 \\
(88.4 \%)\end{array}$ \\
\hline Axon & 272 & $\begin{array}{l}8 \\
(2.9 \%)\end{array}$ & $\begin{array}{c}1 \\
(0.4 \%)\end{array}$ & $\begin{array}{l}263 \\
(96.6 \%)\end{array}$ \\
\hline
\end{tabular}

Counts of decorated microtubules are indicated for each region of the cone cell. Isolated retinas were incubated in hook-assembly buffer without exogenous tubulin, $0^{\circ} \mathrm{C}$ for $30 \mathrm{~min}, 22^{\circ} \mathrm{C}$ for $10 \mathrm{~min}, 37^{\circ} \mathrm{C}$ for $15 \mathrm{~min}$. Sections were viewed as though looking toward the distal tip of the outer segment (OS). Percentages in parentheses are calculated with respect to the total number of decorated microtubules scored for each cone region. In all preparations, myoid length was determined to be $20-$ $30 \mu \mathrm{m}$ by cutting longitudinal sections before rotating the block to cut cross sections. 

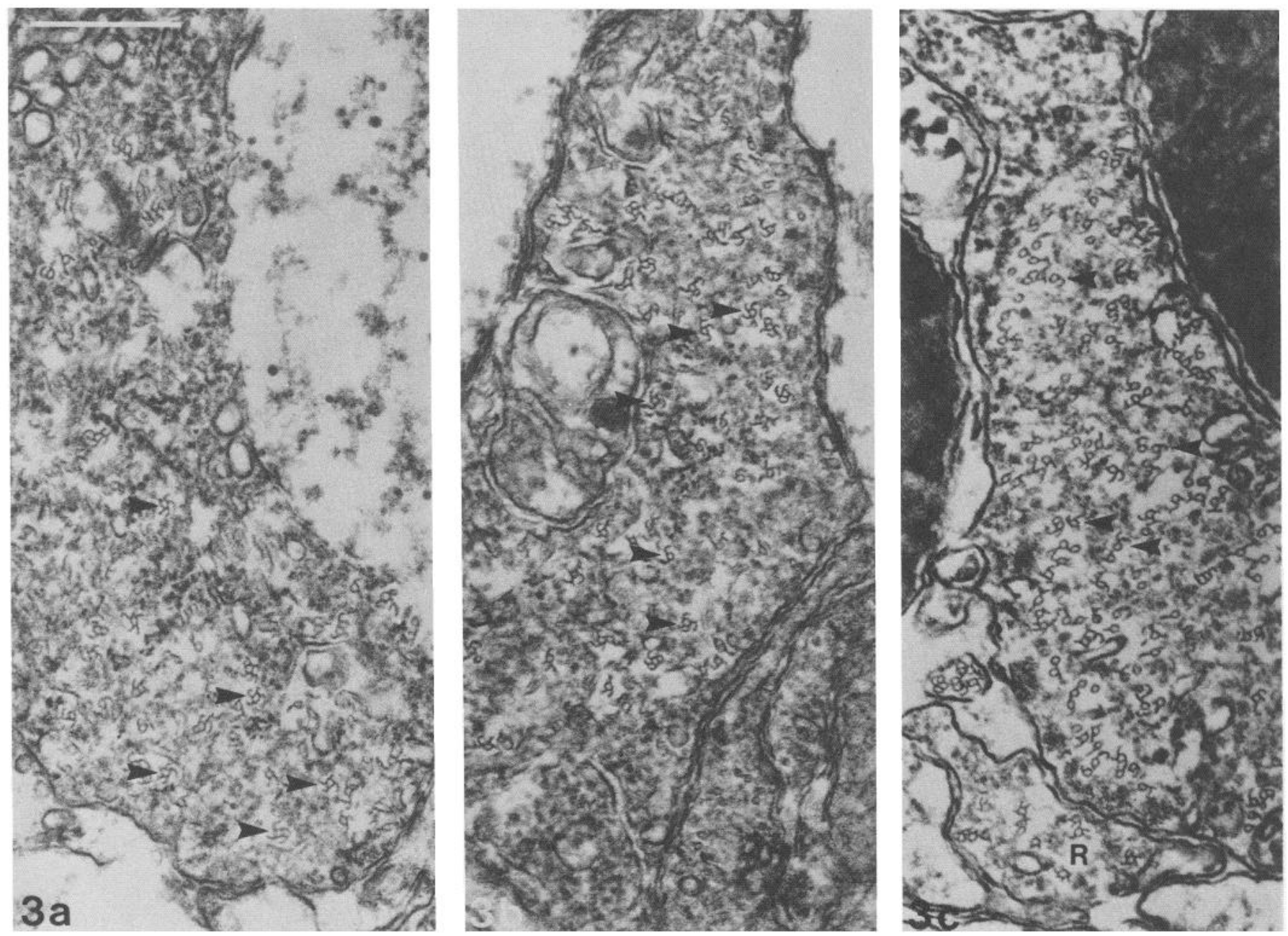

Figure 3. Decorated microtubules in cone and rod myoids cut in cross section. $a$ and $b$, Cone myoids decorated by exogenous tubulin. $c$, Cone myoid and rod myoid $(R)$ decorated by endogenous tubulin. Sections are viewed toward the outer segment, and all hooks (arrows) are clockwise. Scale bar, $0.5 \mu \mathrm{m}$.

Table 3. Microtubule polarity orientation in rods

\begin{tabular}{|c|c|c|c|c|}
\hline & $\begin{array}{l}\text { Number } \\
\text { of de- } \\
\text { corated } \\
\text { micro- } \\
\text { tubules } \\
\text { scored }\end{array}$ & $\begin{array}{l}\text { Plus end } \\
\text { toward } \\
\text { distal tip } \\
\text { OS }-1 \text { or } \\
\text { more } \\
\text { hooks } \\
\text { counter- } \\
\text { clockwise }\end{array}$ & $\begin{array}{l}\text { Ambig- } \\
\text { uous }\end{array}$ & $\begin{array}{l}\text { Plus end } \\
\text { toward } \\
\text { synapse- } \\
1 \text { or more } \\
\text { hooks } \\
\text { clockwise }\end{array}$ \\
\hline $\begin{array}{l}\text { Outer segment } \\
\quad \text { (exogenous tubulin) }\end{array}$ & 87 & 87 & 0 & 0 \\
\hline Myoid (exogenous tubulin) & 96 & $\begin{array}{l}1 \\
(1.0 \%)\end{array}$ & $\begin{array}{l}1 \\
(1.0 \%)\end{array}$ & $\begin{array}{l}94 \\
(97.9 \%)\end{array}$ \\
\hline Myoid (endogenous tubulin) & 15 & 0 & 0 & $\begin{array}{c}15 \\
(100 \%)\end{array}$ \\
\hline Axon (endogenous tubulin) & 77 & 0 & $\begin{array}{l}1 \\
(1.3 \%)\end{array}$ & $\begin{array}{l}76 \\
(98.7 \%)\end{array}$ \\
\hline
\end{tabular}

Counts of decorated microtubules are indicated for different regions of the rod cell. Isolated retinas were incubated in hook-assembly buffer with or without exogenous tubulin as indicated, $0^{\circ} \mathrm{C}$ for $30 \mathrm{~min}, 22^{\circ} \mathrm{C}$ for $10 \mathrm{~min}, 37^{\circ}$ for $15 \mathrm{~min}$. Cross sections were viewed as though looking toward the distal tip of the outer segment (OS). Percentages in parentheses are calculated with respect to the total number of decorated microtubules scored for each rod region. cell models were incubated in reactivation medium at $0^{\circ} \mathrm{C}(\mathrm{Gil}-$ son and Burnside, unpublished observations). It was because of this cold stability of sunfish microtubules that we introduced the $0^{\circ} \mathrm{C}$ incubation step in our procedure to optimize cell lysis and penetration of exogenous tubulin subunits and medium constituents into the photoreceptors. To investigate whether cold stability was retained under the buffer conditions used here, squares of retina were fixed immediately after incubation at $0^{\circ} \mathrm{C}$ for $30 \mathrm{~min}$ in hook assembly solution without exogenous tubulin (treatment 6 in Table 1). Undecorated microtubules were present in the myoid, but their numbers were reduced (Table 1). For all the observations in Table 1, counts were made from myoids 20-30 $\mu \mathrm{m}$ long. Untreated cones (treatment 1 ) and cones not subjected to cold while in decoration medium (treatment 5) contained over 200 microtubules per myoid cross section, but cones subjected to the cold incubation step had less than 125 microtubules. Thus, it appears that cold causes depolymerization of $50-70 \%$ of the microtubules but leaves a cold stable population of microtubules intact. Moreover, cold disrupted a similar percentage $(60 \%)$ of the axon microtubules which are more resistent to colchicine treatment than myoid microtubules (Warren and Burnside, 1978). Thus, the tubulin 

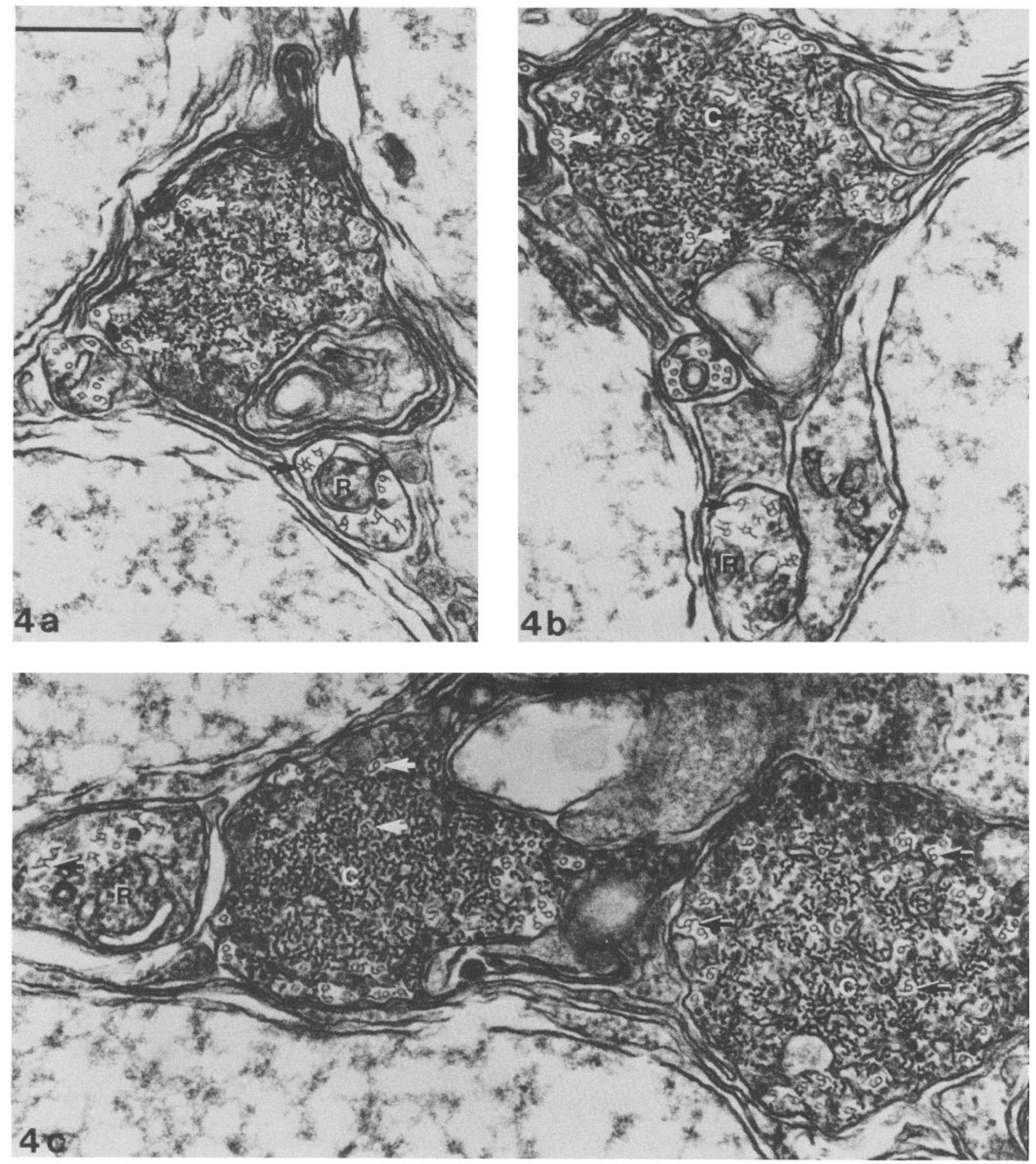

Figure 4. Decorated microtubules in axons of rods $(R)$ and cones $(C)$ cut in cross section. Decoration is by endogenous tubulin. Sections are viewed toward the outer segment; all hooks (arrows) are clockwise. Scale bar, $0.5 \mu \mathrm{m}$.

from these cold-unstable microtubules could contribute to an endogenous pool of subunits that subsequently decorates the stable microtubules when the temperature is raised. A comparison of preparations that were not exposed to cold with those that were exposed to cold indicates that in both cases $>97 \%$ of the decorated microtubules had clockwise hooks (Table 1). Unless there was preferential decoration of only the cold-stable population in non-cold-treated cones, this observation argues that in teleost photoreceptors cold-labile and cold-stable microtubules have the same polarity. 


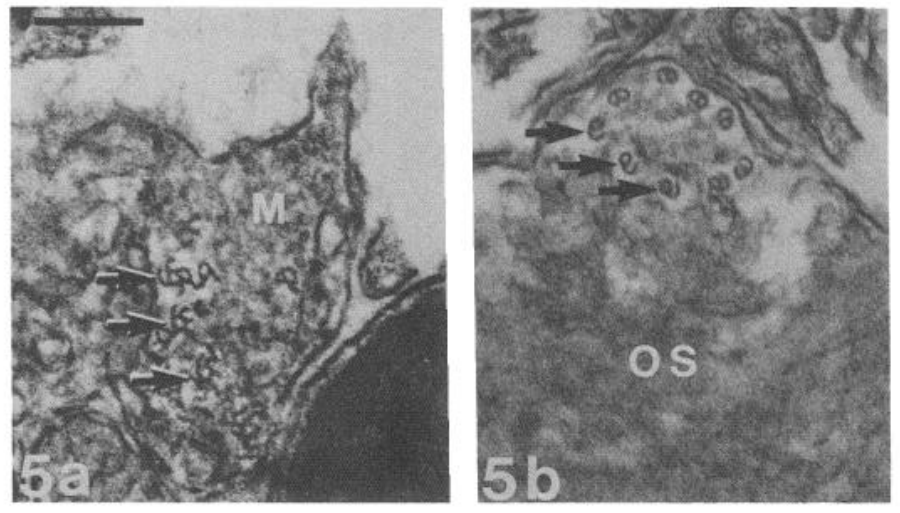

Figure 5. Hooked microtubules in rod myoid $(a)$ and outer segment (b) cut in cross section. Decoration is by exogenous tubulin; sections are viewed toward the distal tip of the outer segment $(O S)$. Hooks are clockwise (arrows) in the myoid (a) and counterclockwise (arrows) in the outer segment $(b)$. Scale bar, $0.25 \mu \mathrm{m}$.

\section{Discussion}

We have demonstrated that the polarity orientations of the microtubule arrays of teleost photoreceptors are precisely organized (Fig. 1). Microtubules within the inner segment, perinuclear region, and axon are virtually all oriented with minus ends toward the outer segment, plus ends toward the axon terminal. Thus, with regard to their polarities, the cytoplasmic microtubules may be viewed collectively as forming a single array from the base of the outer segment to the axon terminal. Photoreceptor axon microtubules are oriented as they are in the axons of many other neuron types, with plus end toward the axon terminal (Burton and Paige, 1981; Filliatreau and DiGiamberardino, 1981; Heidemann et al., 1981). Photoreceptor myoid microtubules have the same orientation as reported for olfactory dendrites (Burton, 1985), which are analogous structures.

Axonemal microtubules of the outer segment and accessory outer segment had counterclockwise hooks, suggesting that microtubule minus ends are directed toward the basal body. Although this structure could occur naturally, as the doublets convert to singlets, and may not represent actual decoration, we consider it likely that these hooks indicate polarity orientation of the microtubules because in both rods and cones, all axonemal hooks turned in the same direction, and the direction of multiple hooks on 2 axonemal microtubules was consistent with the direction of single hooks. These findings indicate that outer segment microtubules are oriented with minus ends toward the basal body as observed in cilia and flagella, which also originate from a basal body (Allen and Borisy, 1974; Euteneuer and McIntosh, 1981a).

With respect to the nucleus microtubules in photoreceptor myoids and olfactory dendrites have opposite polarity from the axon microtubules of these cells. Myoid and olfactory dendrite microtubules are oriented with plus ends toward the nucleus, while axon microtubules are oriented with minus ends toward the nucleus, as has been observed in most cell types. This microtubule orientation in photoreceptor myoids may reflect the fact that myoids are analogous to dendrites rather than axons; dendrites other than those of olfactory neurons have not been studied. However, it seems more likely that the microtubule orientation in photoreceptor myoids and olfactory dendrites reflects the unique developmental history characteristic of sen- sory neurons bearing modified ciliary receptors; during morphogenesis of these cells centrioles migrate away from the nucleus into dendritic processes which bear the modified ciliary receptor.

In most cell types, cytoplasmic microtubules radiate from the perinuclear region, where their minus ends are associated with the centrosome (Euteneuer and McIntosh, 1981a; Soltys and Borisy, 1985; McNiven and Porter, 1986). This focal point of the array has been called a microtubule organizing center (MTOC) because it has been shown to nucleate microtubules and has been postulated to regulate the array as a whole by controlling microtubule number, length, and stability (McGill and Brinkley, 1975; Snyder and McIntosh, 1975; Telzer and Rosenbaum, 1979; Brinkley et al., 1981). We have observed no structures resembling centrioles or other candidates for MTOCs in the photoreceptor nuclear region, myoid or proximal ellipsoid either in green sunfish or in blue striped grunt (Warren and Burnside, 1978). In green sunfish photoreceptors the only structures that we have observed which resemble other reported MTOCs are single basal bodies serving as the base of the connecting cilia of the accessory and true outer segments and dense bodies associated with the basal body (Fig. 2). By analogy to other cells, the orientation of microtubules in photoreceptors is consistent with the suggestion that the basal body of the connecting cilium or associated dense bodies could serve as the MTOC for cytoplasmic microtubules in these cells since minus ends are directed toward it.

An important function of cytoplasmic microtubules in neurons and other cells is mediation of intracellular particle and vesicle transport (Murphy and Tilney, 1974; Hayden et al., 1983; Allen et al., 1985; Koonce and Schliwa, 1985). In photoreceptors, outer segment proteins are synthesized near the nucleus and are then transported as vesicles through the myoid and ellipsoid to the base of the outer segment, where they are incorporated into new disks (Papermaster et al., 1985). Our polarity findings specify some directional constraints on the transport of vesicles along photoreceptor microtubules. The anterograde translocator kinesin has been shown to transport particles toward microtubule plus ends, and a different molecule, a retrograde transporter, has been shown to transport particles toward microtubule minus ends (Vale et al., 1985; Pryer et al., 1986). In the photoreceptor myoid, transport of outer segment precursors to the outer segment occurs from microtubule plus to minus ends, a direction inconsistent with kinesin-based transport. Kinesin would instead transport vesicles through the axon toward the synapse. Specific association with anterograde or retrograde transporters would direct vesicles toward either the synapse or the outer segment and thus might serve as part of the sorting mechanism for materials synthesized in the perinuclear region.

Microtubules have been shown to be essential for teleost cone elongation (Warren and Burnside, 1978; Burnside and Nagle, 1983), but the mechanism of their participation is unclear. Several observed aspects of elongation can be accounted for by postulating a sliding interaction among myoid microtubules (cf. Burnside, 1988a). Microtubule counts in green sunfish cones indicate that net microtubule assembly occurs only during the initial $40 \mu \mathrm{m}$ of elongation; the final $35 \mu \mathrm{m}$ of elongation occurred without additional assembly (Burnside, 1988b). Inhibitor studies further suggest that cone elongation may be mediated by a dynein-like molecule: elongation is completely blocked by the concentrations of vanadate, EHNA, and $N$-ethylmaleimide known to inhibit axonemal dynein but not kinesin (Gilson et al., 1986; Burnside, 1988b). The polarity studies reported here 
indicate that any microtubule sliding which takes place during cone elongation must occcur between parallel microtubules, as occurs in dynein-mediated sliding of microtubules in ciliary and flagellar axonemes.

\section{Decoration without exogenous tubulin and effects of cold}

In the course of carrying out these studies, we introduced a cold incubation step to allow for reagent penetration when we found that only minimal decoration occurred with previously reported procedures. Not only did the cold step increase decoration with exogenous tubulin as we had intended, it also produced decoration in the absence of exogenous tubulin. To our knowledge this paper constitutes the first detailed report of microtubule decoration by endogenous tubulin.

Cold treatment $\left(0^{\circ} \mathrm{C}\right.$ for $\left.30 \mathrm{~min}\right)$ resulted in a $50-60 \%$ reduction in microtubule number per cone cross section in both myoids and axons. The consistent percentage of microtubule loss implies that cones possess both cold-stable and cold-labile microtubule populations. Disassembly of cold-labile microtubules could provide an endogenous pool of soluble tubulin subunits for contribution to hook formation in subsequent incubation at higher temperature. If so, disassembled tubulin was retained in the cells even though the cells were lysed. Observations by Deery and Brinkley suggest that under some conditions lysed cells can retain internal tubulin pools that remain competent for assembly (Deery and Brinkley, 1983). An alternative explanation of our finding decoration without exogenous tubulin could be that these cells store tubulin in some insoluble form, which could serve as a source for hook formation.

Our successful hook formation with endogenous tubulin implies that this assay may be greatly simplified for use in other cell systems, eliminating the need for tubulin isolation from another source. In addition, the assay may now be available for use with thick tissues, which until now could not be decorated due to inaccessibility of their microtubules to exogenous tubulin. However, decoration by endogenous tubulin may depend on the presence of populations of both cold-stable and cold-labile microtubules and on the retention of an endogenous pool of tubulin within the cells. One might expect more cold-stable microtubules in poikilotherms, which are subject to fluctuations in body temperature.

\section{Summary}

We have assessed the polarity of microtubules throughout the cell body of green sunfish photoreceptors. The microtubules were decorated with hooks formed from either exogenous or endogenous tubulin, using an initial cold treatment. We have found that in both rods and cones the decorated microtubules from ellipsoid through myoid and axon are arranged in a parallel array with microtubule plus ends toward the axon terminal and minus ends toward the outer segment. Although an obvious organizing center for the array was not apparent, possible candidates for MTOCs were the single basal body at the base of the outer segment and the dense bodies associated with it. In both rods and cones, outer segment proteins synthesized in the nuclear region are transported to the outer segment through the photoreceptor myoid and ellipsoid. The microtubules in these regions are oriented such that transport along their surfaces would occur from plus toward minus ends, a direction incompatible with use of kinesin as a transporter molecule. Cone elongation is microtubule-dependent and has been postulated to depend upon a microtubule sliding mechanism within the
Inyoid. Such microtubule sliding in the cone myoid would have to occur between parallel microtubules, as is observed in cilia and flagella.

\section{References}

Ali, M. A. (1975) Retinomotor responses. In Vision in Fishes, M. A. Ali, ed., pp. 313-355, Series A, Plenum, New York.

Allen, C. A., and G. G. Borisy (1974) Structural polarity and directional growth of microtubules of Chlamydomonas flagella. J. Mol. Biol. 90: 381-402.

Allen, R. D., D. G. Weiss, J. H. Hayden, D. T. Brown, H. Fujiwake, and M. Simpson (1985) Gliding movement of and bidirectional transport along single native microtubules from squid exoplasm: Evidence for an active role of microtubules in cytoplasmic transport. $J$. Cell Biol. 100: 1736-1752.

Brinkley, B. R., S. M. Cox, D. A. Pepper, L. Wible, S. L. Brenner, and R. L. Pardue (1981) Tubulin assembly sites and the organization of cytoplasmic microtubules in cultured mammalian cells. J. Cell Biol. 90: 554-562.

Burnside, B. (1976) Microtubules and actin filaments in teleost visual cone elongation and contraction. J. Supramol. Struct. 5: 257-275.

Burnside, B. (1986a) Photoreceptor contraction and elongation: Calcium and cAMP regulation of actin- and microtubule-dependent changes in cell shape. In Intrinsic Determinants of Neuronal Cell Form and Function, R. J. Lasek and M. M. Black, eds., pp. 323-359, Alan R. Liss, New York.

Burnside, B. (1988b) Possible roles for microtubule motors and microtubule sliding in cell elongation. In Cell Movement, Vol. 1, F. D. Warner, ed., Alan R. Liss, New York (in press).

Burnside, B., and B. W. Nagle (1983) Retinomotor movements of photoreceptors and retinal pigment epithelium: Mechanisms and regulation. In Progress in Retinal Research, Vol. 2, N. Usborne and $\mathbf{G}$. Chader, eds., pp. 67-109, Pergamon, Oxford.

Burnside, B., R. A. Alder, and P. O'Connor (1982) Pigment migration in the teleost retinal pigment epithelium. I. Roles for actin and microtubules in pigment granule transport and cone movement. Invest. Ophthalmol. Vis. Sci. 24: 1-15

Burton, P. R. (1985) Ultrastructure of the olfactory neuron of the bullfrog: The dendrite and its microtubules. J. Comp. Neurol. 242: 147-160.

Burton, P. R., and J. L. Paige (1981) Polarity of axoplasmic microtubules in the olfactory nerve of the frog. Proc. Natl. Acad. Sci. USA 78: 3269-3273.

Cande, W. Z., and K. McDonald (1986) Physiological and ultrastructural analysis of elongating mitotic spindles reactivated in vitro. J. Cell Biol. 103: 593-604.

Deery, W. J., and B. R. Brinkley (1983) Cytoplasmic microtubule assembly-disassembly from endogenous tubulin in a brij-lysed cell model. J. Cell Biol. 96: 1631-1641.

Dentler, W. L., S. Granett, G. B. Witman, and J. L. Rosenbaum (1974) Directionality of brain microtubule assembly in vitro. Proc. Natl. Acad. Sci. USA 71: 1710-1714.

Euteneuer, U., and J. R. McIntosh (1980) Polarity of midbody and phragmoplast microtubules. J. Cell Biol. 87: 509-515.

Euteneuer, U., and J. R. McIntosh (1981a) Polarity of some motilityrelated microtubules. Proc. Natl. Acad. Sci. USA 78: 372-376.

Euteneuer, U., and J. R. McIntosh (1981b) Structural polarity of kinetochore microtubules in PtKl cells. J. Cell Biol. 89: 338-345.

Filliatreau, G., and L. DiGiamberardino (1981) Microtubule polarity in myelinated axons as studied after decoration with tubulin. Biol. Cell 42: 69-72.

Friede, R. L., and K. C. Ho (1977) The relation of axonal transport of mitochondria with microtubules and other axoplasmic organelles. J. Physiol. (Lond.) 265: 507-519.

Gilson, C. A., N. Ackland, and B. Burnside (1986) Regulation of reactivated elongation in lysed cell models of teleost retinal cones by cAMP and calcium. J. Cell Biol. 102: 1047-1059.

Greiner, J. V., T. A. Weidman, H. D. Bodley, and C. A. M. Greiner (1981) Ciliogenesis in photoreceptor cells of the retina. Exp. Eye Res. 33: 433-446.

Hammond, G. R., and R. S. Smith (1977) Inhibition of the rapid movement of optically detectable axonal particles by colchicine and vinblastine. Brain Res. 128: 227-242.

Hayden, J. H., R. D. Allen, and R. D. Goldman (1983) Cytoplasmic 
transport in keratocytes: Direct visualization of particle translocation along microtubules. Cell Motil. 3: 1-19.

Heidemann, S. R., and J. R. McIntosh (1980) Visualization of the structural polarity of microtubules. Nature 286: 517-519.

Heidemann, S. R., J. M. Landers, and M. A. Hamborg (1981) Polarity orientation of axonal microtubules. J. Cell Biol. 91: 661-665.

Inoue, S., and H. Sato (1967) Cell motility by labile association of molecules. The nature of mitotic spindle fibers and their role in chromosome movement. J. Gen. Physiol. 50: 259-292.

Kinney, M. S., and S. F. Fisher (1978) The photoreceptors and pigment epithelium of the larval Xenopus retina: Morphogenesis and outer segment renewal. Proc. R. Soc. London [Biol.] 201: 149-167.

Koonce, M. P., and M. Schliwa (1985) Bidirectional organelle transport can occur in cell processes that contain single microtubules. J. Cell Biol. 100: 322-326.

Malawista, S. E. (1971) The melanocyte model: Colchicine-like effects of other antimitotic agents. J. Cell Biol. 49: 848-855.

Margolis, R. L., and L. Wilson (1981) Microtubule treadmills-Possible molecular machinery. Nature 293: 705-711.

McDonald, K. L., M. K. Edwards, and J. R. McIntosh (1979) Crosssectional structure of the central mitotic spindle of Diatoma vulgare. Evidence for specific interactions between antiparallel microtubules. J. Cell Biol. 83: 443-461.

McGill, M., and B. R. Brinkley (1975) Human chromosomes and centrioles as nucleating sites for the in vitro assembly of microtubules from bovine brain tubulin. J. Cell Biol. 67: 189-199.

McIntosh, J. R., and U. Euteneuer (1984) Tubulin hooks as probes for microtubule polarity: An analysis of the method and an evaluation of data on microtubule polarity in the mitotic spindle. J. Cell Biol. 98: 525-533.

McNiven, M. A., and K. R. Porter (1986) Microtubule polarity confers dircction to pigment transport in chromatophores. J. Cell Biol. 103. 1547-1555.

Murphy, D. B., and L. J. Tilney (1974) The role of microtubules in the movement of pigment granules in teleost melanophores. J. Cell Biol. 61: 757-779.

Nagle, B. W., C. Okomoto, B. Taggart, and B. Burnside (1986) The teleost cone cytoskeleton. Localization of actin, microtubules, and intermediate filaments. Invest. Ophthalmol. Vis. Sci. 27: 689-701.

O'Connor, P., and B. Burnside (1981) Actin-dependent cell elongation in teleost retinal rods: Requirement for actin filament assembly. $\mathrm{J}$. Cell Biol. 89: 517-524.

O'Connor, P., and B. Burnside (1982) Elevation of cyclic AMP activates an actin-dependent contraction in teleost retinal rods. J. Cell Biol. 95: 445-452.
Papermaster, D. S., B. G. Schneider, and J. C. Bcsharsc (1985) Vesicular transport of newly synthesized opsin from the golgi apparatus toward the rod outer segment. Invest. Ophthalmol. Vis. Sci. 26: 13861404.

Pryer, N. K., P. Wadsworth, and E. D. Salmon (1986) Polarized microtubule gliding and particle saltations produced by soluble factors from sea urchin eggs and embryos. Cell Motil. Cytoskel. 6: 537-548.

Sale, W. S., and P. Satir (1977) Direction of active sliding of microtubules in Tetrahymena cilia. Proc. Natl. Acad. Sci. USA 74: 20452049.

Schliwa, M., and J. Bereiter-Hahn (1973) Pigment movements in fish melanophores: Morphological and physiological studies. III. The effects of colchicine and vinblastine. Z. Zellforch. 147: 127-148.

Shelanski, M. L., F. Gaskin, and C. R. Cantor (1973) Microtubule assembly in the absence of added nuclcotides. Proc. Natl. Acad. Sci. USA 70: 765-768.

Snyder, J. A., and J. R. McIntosh (1975) Initiation and growth of microtubules from mitotic centers in lysed mammalian cells. J. Cell Biol. 67: 744-760.

Soltys, B. J., and G. G. Borisy (1985) Polymerization of tubulin in vivo: Direct evidence for assembly onto microtubule ends and from centrosomes. J. Cell Biol. 100: 1682-1689.

Stephens, R. E., and K. T. Edds (1976) Microtubules: Structure, chemistry and function. Physiol. Rev. 56: 709-777.

Stossel, T. P. (1974) Phagocytosis. Part II. N. Eng. J. Med. 290: 774780 .

Telzer, B. R., and L. T. Haimo (1981) Decoration of spindle microtubules with dynein: Evidence for uniform polarity. J. Cell Biol. 89: 373-378.

Telzer, B. R., and J. L. Rosenbaum (1979) Cell cycle dependent, in vitro assembly of microtubules onto the pericentriolar material of HeLa cells. J. Cell Biol. 81: 484-497.

Tokyuaso, K., and E. Yamada (1959) The fine structure of the retina studied with the electron microscope. IV. Morphogenesis of outer segments of retinal rods. J. Biophys. Biochem. Cytol. 6: 225-230.

Vale, R. D., B. J. Schnapp, T. Mitchison, E. Steuer, T. S. Reese, and M. P. Sheetz (1985) Different axoplasmic proteins generate movement in opposite directions along microtubules in vitro. Cell 43:623632.

Warren, R. H., and B. Burnside (1978) Microtubules in cone myoid elongation in the teleost retina. J. Cell Biol. 78: 247-259.

Yoshida, T., A. Ito, and K. Izutsu (1985) Association of anti-dynein-1 cross-reactive antigen with the mitotic spindle of mammalian cells. Cell Struct. Function 10: 245-258. 